\title{
A EFICÁCIA DAS COTAS ELEITORAIS NA ARGENTINA E NO BRASIL ${ }^{1}$
}

THE EFFECTIVENESS OF ELECTORAL QUOTAS IN ARGENTINA AND BRAZIL

LA EFICACIA DE LAS CUOTAS ELECTORALES EN LA ARGENTINA Y EN BRASIL

Cristiane Aquino de Souza²

Resumo: A maioria dos países latino-americanos adotou leis que estabelecem cotas eleitorais de gênero na década de 1990 e, mais precisamente, em 1996 e 1997, anos imediatamente posteriores à IV Conferência Mundial sobre a mulher de Pequim (1995), cuja Plataforma de Ação busca garantir o acesso igualitário e a plena participação das mulheres nas estruturas de poder e tomada de decisões. Os efeitos da aplicação das cotas muda significativamente entre os países. A Argentina constitui exemplo de um país onde as cotas contribuíram, notoriamente, para o incremento da participação das mulheres no Parlamento, ao passo que, no Brasil, não tiveram um efeito positivo. Dessa forma, este trabalho pretende analisar o processo de adoção e a eficácia das leis que estabeleceram cotas eleitorais de gênero na Argentina e no Brasil. Busca-se, com isso, compreender os fatores que influenciaram o grau de efetividade dessas leis no sentido de aumentar a representatividade feminina nos Parlamentos.

1 Este trabalho faz parte do projeto de investigação "Democracia e Paridade de gênero", financiado pelo Conselho Nacional de Desenvolvimento Científico e Tecnológico (CNPq) e pela Fundação Cearense de Apoio ao Desenvolvimento Científico e Tecnológico (FUNCAP). Doutora em Direitos Fundamentais pela Universidade Autônoma de Madri (2011), mestra em Direito Público pela Universidade Federal do Ceará (2005), graduada em Direito pela Universidade Federal do Ceará (2002). Atualmente é professora adjunta da Graduação e do Programa de Pós-Graduação em Direito da Universidade de Fortaleza. casfortaleza@hotmail.com 
Palavras-chave: Lei. Cotas eleitorais. Gênero. Argentina. Brasil.

Abstract: Most Latin American countries adopted laws establishing electoral gender quotas in the 1990s, and more specifically, in 1996 and 1997, the years immediately following the Fourth World Conference on Women in Beijing (1995). The Platform for Action of that conference strives for equal access and full participation of women in power structures and decision-making. The effects of the quota application vary significantly from country to country. Argentina is an example of a country where the quotas made a significant contribution to increasing the participation of women in Parliament, whereas in Brazil, they had no positive effect. This study analyzes the process of implementation of these measures, and the effectiveness of laws that established electoral gender quotas in Argentina and Brazil. It therefore attempts to understand the factors that affect the effectiveness of these laws in increasing the number of women in parliaments.

Keywords: Law. Electoral quotas. Gender. Argentina. Brazil.

Resumen: La mayoría de los países latinoamericanos adoptó leyes que establecen cuotas electorales de género en la década de 1990, y más precisamente en 1996 y 1997, años inmediatamente posteriores a la IV Conferencia Mundial sobre la Mujer de Pekín (1995), cuya Plataforma de Acción busca garantizar el acceso igualitario y la plena participación de las mujeres en las estructuras de poder y en la toma de decisiones. Los efectos de la aplicación de las cuotas cambian significativamente entre los países. La Argentina constituye un ejemplo de país donde las cuotas contribuyeron notoriamente al incremento de la participación de las mujeres en el Parlamento, mientras que en Brasil no tuvieron un efecto positivo. De este modo, este trabajo pretende analizar el proceso de adopción y la eficacia de las leyes que establecieron cuotas electorales de género en la Argentina y en Brasil. Con ello se busca comprender los factores que ejercieron influencia sobre el grado de efectividad de esas leyes, en el sentido de aumentar la representatividad femenina en los Parlamentos.

Palabras clave: Ley. Cuotas electorales. Género. Argentina. Brasil. 


\section{INTRODUÇÃO}

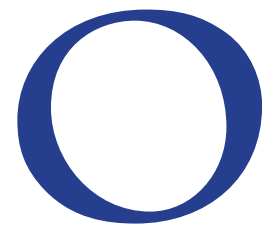

s países da América Latina e da Europa adotaram cotas eleitorais mediante leis que preveem a reserva e/ou o preenchimento de uma porcentagem de vagas para cada sexo ou especificamente para as mulheres nas candidaturas eleitorais dos partidos ${ }^{3}$. A Argentina foi o país pioneiro no mundo em legalizar o mecanismo das cotas, ao aprovar a "Ley de Cupos", em 1991. A experiência exitosa da Argentina motivou outros países a debater sobre a implementação de cotas eleitorais de gênero. O processo de redemocratização na América Latina também é considerado um fator que contribuiu para a implementação das cotas legais na região, já que a adoção de tais medidas é conveniente para conferir uma imagem positiva e moderna ao país e aumentar a legitimidade do sistema político num contexto de reconstrução da democracia 4 . A isso, soma-se o importante incentivo proveniente da IV Conferência sobre a mulher de Pequim (1995), cuja Plataforma de Ação busca garantir o acesso igualitário e a plena participação das mulheres nas estruturas de poder e tomada de decisões. Dessa forma, a maioria dos países latino-americanos adotaram tais leis na década de noventa e, mais precisamente, em 1996 e 1997, anos imediatamente posteriores à mencionada Conferência.

Os efeitos da aplicação das cotas muda significativamente entre os países. Embora seja importante ressaltar que a alta ou baixa porcentagem de mulheres no Parlamento não se deve, exclusivamente, ao grau de eficácia das cotas, pode-se observar que, passado certo tempo da existência de uma cota, se o país consegue aumentar o número de mulheres no parlamento, há grandes possibilidades de que as cotas tenham contribuído para isso. Por outro lado, quando a porcentagem de mulheres continua baixa, a indicação é de que as cotas não possuem boa efetividade.

3 AQUINO DE SOUZA, Cristiane. Cotas eleitorais para a igualdade de gênero: uma perspectiva jurídico-constitucional. Anuario de Derecho Constitucional Latinoamericano, ano XVI, 2010, p. 239-253.

4 ARAÚJO e GARCÍA, Ana Isabel. The experience and the impact of quotas in Latin America. In: DAHLERUP, Drude (Org.). Women, Quotas and Politics. New York: Routledge, 2007. 
A Argentina constitui exemplo de um país onde as cotas contribuíram, notoriamente, para o incremento da participação das mulheres no Parlamento, ao passo que, no Brasil, não tiveram um efeito positivo. Dessa forma, este trabalho pretende analisar o processo de adoção e a eficácia das leis que estabeleceram cotas eleitorais de gênero na Argentina e no Brasil. Busca-se, com isso, compreender os fatores que influenciam a aptidão dessas leis para aumentar a representatividade feminina nos Parlamentos.

\section{ARGENTINA}

A lei que estabelece cotas femininas na Argentina, aprovada em 29 de novembro de 1991, constitui consequência do trabalho de mobilização realizado por mulheres políticas, em conjunto com mulheres de movimentos organizados pela sociedade civil. Nos anos oitenta, algumas militantes de diversos partidos começaram a organizar-se, com a finalidade de conseguir a adoção de medidas de ação positiva no sentido de diminuir o contraste entre a ampla participação feminina nas bases partidárias e seu acesso restrito às instâncias de representação. As discussões e os tratados estabelecidos no plano internacional exerceram um papel importante para a elaboração de estratégias nesse sentido. Destacam-se a Conferência Mundial da Mulher, realizada em Nairobi (1985); os congressos da Internacional Socialista; a Convenção sobre a Eliminação de todas as Formas de Discriminação contra a Mulher (CEDAW); e o intercâmbio de experiências com mulheres do Partido Socialista Espanhol (PSOE) e do Partido Socialdemocrata da Alemanha (PSD).

Tendo como referência os exemplos de partidos europeus, as militantes argentinas tentaram conseguir a adoção voluntária de cotas partidárias. No Congresso Nacional das Mulheres da União Cívica Radical (UCR) de 1989, debateu-se, pela primeira vez, a inclusão de cotas para as mulheres nas listas partidárias ${ }^{6}$. O Partido Justicialista (PJ), por outro lado, estipulava em seu estatuto

5 MARX, Jutta; CAMINOTTI, Mariana e BORNER, Jutta. ¿En pie de igualdad? Quince años de cupo femenino en Argentina. In: RÍOS TOBAR, Marcela (Org.). Mujer y política: El impacto de las cuotas de género en América Latina. RÍOS Santiago/Chile: Catalonia, 2008.

6 ALLEGRONE, Norma. Ley de Cupo Femenino: Su aplicación e interpretación en la República Argentina. Buenos Aires: Fundación para el Desarrollo en Igualdad - FUNDAI, Fundación Friedrich, 2002. 
que as mulheres possuem direito a ser representadas de maneira equitativa nas candidaturas a cargos legislativos. Apesar disso, no período entre 1987-89, somente havia $2,8 \%$ de representantes femininas no Congresso por esse partido. A União Cívica Radical (UCR) negou-se a aceitar a demanda de introduzir cotas em seu estatuto. Isto, somado à baixa presença de deputadas do Partido Justicialista (PJ) no Congresso, incentivou a apresentação de projetos para a implementação de cotas legais. Um destes, elaborado pela senadora Margarita Malharro de Torres (UCR), estabelecia a inclusão de um mínimo de 30\% de mulheres nas listas de candidaturas em posições com possibilidade de resultar eleitas.

Com a intenção de apoiar os projetos de lei para a implementação de cotas, em 1990 formou-se a Rede de Feministas Políticas, com a participação de mulheres de quinze partidos distintos. Nesse mesmo ano, o $5^{\circ}$ Encontro Nacional de Mulheres resultou no consenso sobre o envio de notas aos presidentes de todos os partidos e de ambas as câmaras, para a aprovação dos projetos de lei. Por outro lado, as mulheres peronistas conseguiram obter o apoio do presidente Carlos Menem, pois a demanda apresentada convergia com sua ambição de modernizar o país, ao mesmo tempo em que possibilitava capitalizar o voto feminino.

A massiva presença feminina na sessão do Senado, em 20 de setembro de 1990, foi importante para a aprovação unânime do projeto de lei da senadora Malharro de Torres. Antes da votação na Câmara dos Deputados, as mulheres da Rede de Feministas Políticas e as poucas deputadas da Câmara Baixa exerceram pressão por meio de atos políticos e de uma prática de lobby para conseguir a aprovação da lei. Assim, em 6 de novembro de 1991, as mulheres militantes de todos os partidos "ocuparam" o Congresso e as ruas para manifestaremse favoravelmente a essa medida legislativa. Nesse contexto, a Lei n. 24.012 foi sancionada com 143 votos a favor, 7 contra e 3 abstenções ${ }^{7}$.

A lei argentina que estabelece cotas eleitorais de gênero, a "Ley de Cupo Femenino" de 1991, altera o art. 60 do Código Eleitoral argentino, para estabelecer que "as listas que se apresentam deverão ter mulheres num mínimo de 30\% dos candidatos aos cargos a eleger e em proporções com possibilidades de resultar

7 DURRIEU, Marcela. Se dice de nosotras. Buenos Aires: Catálogos Editora, 1999. 
eleitas. Não será oficializada nenhuma lista que não cumpra estes requisitos". Por ocasião do Dia Internacional da Mulher, em 8 de março de 1993, o presidente Carlos Menem promulgou o Decreto 379/93 para regulamentar a lei. Este Decreto ressalta que a porcentagem de $30 \%$ deve ser interpretada como uma quantidade mínima de presença feminina nas listas.

Por outro lado, o mencionado Decreto prevê uma tabela que estabelece o número mínimo de candidatas nas listas em relação ao número de cargos a renovar no distrito. De acordo com essa tabela, quando a porcentagem de $30 \%$ determinar frações menores à unidade, deve-se arredondar para cima, quando os centésimos são iguais ou maiores a 50; ou para baixo, quando os centésimos são inferiores ao mencionado valor ${ }^{8}$. Uma das disposições mais importantes desse decreto foi a que estabeleceu um preciso mandato de posição, impondo que resulta indiferente pôr uma mulher ou um homem no primeiro lugar da lista, mas que "nos seguintes lugares da lista incluir-se-á regularmente uma (a) mulher para cada dos (2) homens ${ }^{9}$ até que se cubra a porcentagem mínima que exige a Lei n. 24.012 dentro do número total de cargos". Por outro lado, de acordo com a mencionada tabela, no caso de que fossem renovados 2 cargos, pelo menos um deles deveria ter a mulher como candidata ${ }^{10}$.

A Lei de cotas e o Decreto n. 379/93 aplicaram-se, por primeira vez, em 1993, para as eleições de renovação parcial da Câmara dos Deputados. Essas normas produziram um notável incremento de mulheres na Câmara Baixa. O número de legisladoras dessa Casa aumentou de 5,8\% (nas eleições de 1991) para 14,4\%, ou seja, a quantidade aumentou mais de duas vezes de maneira imediata. Ressaltase, ainda, que a cota somente teve efeito para a renovação de $50 \%$ das vagas ${ }^{11}$. Por outro lado, também se pode constatar um efeito em longo prazo, o que

8 Essa tabela foi criticada porque não cumpria, em todas as hipóteses, com o mínimo de $30 \%$. No caso de existir 4 cargos a renovar, por exemplo, deveria haver um mínimo de 1 mulher, o que resultaria numa cota efetiva de $25 \%$.

9 Embora o decreto tenha ressaltado que a porcentagem de $30 \%$ constitui um mínimo, redigiu-se de forma incorreta o art. 40, que deveria estar escrito da seguinte forma: nos seguintes lugares da lista, incluir-se-ão regularmente, AO MENOS uma (1) mulher para cada dois (2) homens.

10 Alguns também criticaram essa tabela porque, em casos como o mencionado, a cota efetiva passaria a ser de $50 \%$.

11 A Câmara dos Deputados da Argentina renova a metade de seus membros a cada dois anos. 
confirma a hipótese comentada pela literatura de que, com o transcurso do tempo, existem grandes possibilidades de que a cota aumente sua eficácia ${ }^{12}$. Dessa forma, nas eleições de 1995, a porcentagem de mulheres na Câmara Baixa foi de $25,3 \%$ e atualmente é de $36,5 \%{ }^{13}$.

Apesar da promulgação do mencionado Decreto n. 379/93, é importante ressaltar que, nas eleições legislativas de 1993, muitos partidos cumpriam a exigência de $30 \%$ de candidatas, porém posicionaram as mulheres nos últimos lugares das listas, de maneira que não tiveram possibilidades reais de resultar eleitas. Diante dessa situação, muitas militantes e o Conselho Nacional da Mulher (CNM) $)^{14}$ apresentaram demandas judiciais para exigir o cumprimento do mandato de posição. Não obstante, os juízes negaram-se a aceitar pleitos que não fossem apresentados por uma candidata e consideraram também que o processo para impugnar as listas deveria ser iniciado na fase de sua oficialização e não no momento da eleição interna partidária ${ }^{15}$. Muitas candidatas, apesar de encontrarem-se submetidas a pressões e ameaças de ser sancionadas pelo partido, acionaram a justiça. Algumas conseguiram decisões favoráveis, como no caso Darci Beatriz Sampietro. Esta candidata do Partido Justicialista (PJ) da Província de Entre Ríos impugnou a lista por haver sido colocada na quinta e última posição. O juiz de primeira instância não proferiu sentença favorável à demandante, porém, em razão de recurso de apelação, o Comitê Nacional Eleitoral ordenou a colocação da candidata nos três primeiros lugares da lista (Sentença 1.602/93) ${ }^{16}$.

12 ALLES, Santiago. "¿Hacia la consolidación política? Cambios en la «estructura de oportunidades electorales» de las mujeres en Argentina. América Latina Hoy, n. 47, 2007, p. 123-154.

13 IDEA (INTERNATIONAL INSTITUTE FOR DEMOCRACY AND ELECTORAL ASSISTANCE). Disponível em: <http://www.idea.int/uid/countryview.cfm?id=12>. Acesso em 4 de fev. de 2014.

14 O Conselho Nacional da Mulher, criado em 1992, constitui o órgão do Governo competente para realizar políticas públicas de igualdade de oportunidades e de tratamento entre homens e mulheres. Esse organismo incitou os partidos que não observavam as disposições da Lei 24.012 e de seu Decreto regulamentar a corrigir a composição das listas.

15 Na causa "Silvestri, José Luis/acción de amparo (Unión Cívica Radical)", do distrito de Mendoza (Sentença 1.513/93), a Câmara Nacional Eleitoral considerou que não existia lesão concreta ao direito de ser candidato se a pessoa não constava na lista impugnada. (LÁZZARO, Alejandra. El papel de la justicia en la resolución de conflictos de género: El caso de Argentina. In: ARCHENTI, Nélida; TULA, María Inés (Org.). Mujeres y política en América Latina: Sistemas electorales y cuotas de género. Buenos Aires: Heliasta, 2008, p. 55-64.). LÁZZARO, Alejandra. El papel de la justicia en la resolución de conflictos de género: El caso de Argentina. In: ARCHENTI, Nélida e TULA, María Inés (Org.). Mujeres y política en

América Latina: Sistemas electorales y cuotas de género. Buenos Aires: Heliasta, 2008, p. 55-64. 
Em 1994, houve uma reforma constitucional que previu, expressamente, as ações positivas para as mulheres no âmbito eleitoral, já que o art. 37 passou a reconhecer que "la igualdad real de oportunidades entre varones y mujeres para el acceso a cargos electivos y partidários se garantizará por acciones positivas en la regulación de los partidos políticos y en el régimen electoral". Por outro lado, o art. 75, inciso 22 outorga hierarquia constitucional a vários tratados internacionais, entre os quais figura a Convenção Sobre a Eliminação de Todas as Formas de Discriminação Contra as Mulheres (CEDAW). O inciso 23 do mesmo artigo prevê as ações positivas que visem garantir a igualdade de oportunidades para as crianças, mulheres, idosos e pessoas com discapacidade. Além disso, a reforma estabelece que os senadores nacionais elegem-se de forma direta pelo povo (art. 54), o que possibilitou a futura aplicação das cotas nas eleições para o Senado.

Como resultado da incorporação do mencionado art. 37 na Constituição da Argentina, ampliou-se o critério de legitimação para atuar, pois a Câmara Nacional Eleitoral passou a reconhecer como parte tanto a presidenta do Conselho Nacional da Mulher como qualquer filiado ${ }^{17}$. A decisão do Tribunal baseou-se no argumento de que a Lei de cotas criava, por um lado, uma obrigação para todos os partidos de elaborar listas em conformidade com suas disposições e, por outro lado, o direito dos cidadãos de votar em listas adequadamente compostas por mulheres ${ }^{18}$.

Cabe citar um caso que exerceu um papel especialmente importante sobre a aplicação das cotas: o de María Teresa Merciadri de Moroni, apresentado perante o Tribunal Federal Eleitoral da Província de Córdoba. Essa eleitora reclamava, como filiada, que a lista de candidatos a deputado nacional da União Cívica Radical não observava o estabelecido na Lei n. 24.012, já que situava as mulheres nos lugares $3^{\circ}, 6^{\circ}$ e $9^{\circ}$, enquanto que o partido renovava somente cinco vagas e havia apenas uma mulher nas cinco primeiras posições. A demandante solicitou a modificação da constituição da lista, mediante o argumento de que a cota deve incidir sobre as vagas parlamentares que cada partido renova e não sobre a totalidade de vagas que cada distrito elege.

17 Em 1993, ajuizaram-se 30 ações, número que aumentou para 49, em 1995.

18 LÁZZARO, Alejandra. El papel de la justicia en la resolución de conflictos de género: El caso de Argentina. In: ARCHENTI, Nélida; TULA, María Inés (Org.). Mujeres y política en América Latina: Sistemas electorales y cuotas de género. 
O partido da União Cívica Radical fundamentou sua defesa com base no argumento de que a reserva de gênero deve efetuar-se sobre o total de cargos que a província renova, de forma que a autora havia confundido a possibilidade com a probabilidade de ser eleita. Além disso, afirmou não existir legitimidade processual por falta de direito subjetivo lesionado. Em face da sentença desfavorável, Merciadri apresentou recurso de apelação, cuja decisão (Sentença 1.465/93) não reconheceu legitimidade para acionar, já que é anterior à mencionada reforma constitucional de 1994.

Posteriormente, Merciadri apresentou um recurso extraordinário perante a Corte Suprema da Nação, que foi rejeitado, levando-se em conta que as eleições já haviam ocorrido e que o partido somente obtivera quatro vagas. $A$ demandante respondeu que se deveria reconhecer o direito em expectativa de posicionamento na lista, para o caso em que surgisse uma vaga. Dessa forma, novamente em desacordo com a decisão do Poder Judiciário, apresentou uma petição perante a Corte Interamericana de Direitos Humanos (CIDH), depois da reforma constitucional de 1994. A CIDH facilitou um acordo entre as partes e, em março de 2001, Merciadri afirmou que o Decreto 1.246, promulgado pelo Governo no ano 2000, contempla os fundamentos de sua petição.

A redação do Decreto n. 1.246/00, que substituiu o 379/93, levou em consideração a declaração de admissibilidade da petição apresentada por Merciadri. Foi motivada também, entre outras razões, pela aplicação de critérios diferentes por parte dos distintos partidos políticos e também dos tribunais, o que tornou "indispensable dictar uma norma que tenga em cuenta las más claras y garantizadoras interpretaciones judiciales" ${ }^{19}$, com a finalidade de possibilitar o efetivo cumprimento da Lei n. 24.012.

O mencionado Decreto dispõe que as cotas devem aplicar-se às eleições de deputados, senadores e constituintes nacionais e que somente se considerará cumprida quando seja aplicada não somente à totalidade dos candidatos da lista como também ao número de cargos a renovar do partido. Por outro lado, estipula que, quando o cálculo da cota mínima determine frações menores à unidade, o conceito de quantidade mínima deve ser entendido como a unidade superior e passa

19 Exposição de motivos do Decreto Nacional 1.246. 
a ser regido por uma nova tabela. Esclarece também as disposições sobre o mandato de posição, ao estabelecer, entre outras normas, que a cada três candidatos da lista, um, no mínimo, deve ser mulher, a não ser que se renovem somente dois cargos, caso em que num deles deve figurar uma pessoa do sexo feminino. Por outro lado, dispõe que, se o partido renova somente uma vaga, a pessoa que ocupa o segundo lugar da lista deve ser do sexo oposto à que consta na primeira posição.

O Decreto n. 1.246/00 prevê ainda que, se o lugar da lista ocupado por uma mulher ficar vago por seu falecimento, renúncia ou incapacitação prévia às eleições, a candidata deverá ser substituída pela outra mulher que lhe siga na lista e que essa medida somente é aplicável no caso de substituição de mulheres, ou seja, um homem poderia ser substituído por uma candidata. Estabelece, por outro lado, que qualquer cidadão eleitor possui legitimidade para impugnar a lista de candidatos perante a Justiça Eleitoral. Descreve um preciso mecanismo de sanção ao prever que, se a candidata estiver posicionada num lugar posterior ao que the corresponde na lista, o juiz com competência eleitoral notificará o partido para que proceda ao seu reposicionamento no prazo de 48 horas, e que, em caso de descumprimento, o Tribunal reposicionará de ofício e, quando necessário, nomeará as mulheres seguintes na ordem da lista. Por isso, ressalta que as listas de suplentes também devem cumprir a cota.

Mediante as previsões do mencionado Decreto, as possibilidades de descumprimento da Lei de Cotas diminuíram de maneira significativa ${ }^{20}$. Cabe ressaltar, por fim, que outra disposição relevante do Decreto n. $1.246^{21}$ é a que estabelece que os partidos devem adequar seus estatutos para possibilitar a plena vigência das cotas nas eleições legislativas de 2001. Dessa forma, a Lei de cotas, juntamente com o Decreto n. 1.246/00, aplica-se, por primeira vez, para a eleição dos membros do Senado em 2001.

20 MARX, Jutta; CAMINOTTI, Mariana; BORNER, Jutta. Las legisladoras: Cupos de género y política en Argentina y Brasil. Buenos Aires: Siglo XXI, 2007.

21 Posteriormente foi promulgado o Decreto n. 451/05, que modificou os artigos 4 e 5 do Decreto 1.246 por meio do art. 11, ao estabelecer que, "Cuando se renueve UNO (1), DOS (2) o más cargos, el cómputo siempre se hará a partir del primer lugar y la lista deberá tener por lo menos UNA (1) mujer cada DOS (2) varones para que se cumpla el porcentaje mínimo que exige el artículo 60 del Código Electoral Nacional. En todos los casos se privilegiarán medidas de acción positiva a favor de la igualdad real de oportunidades entre varones y mujeres para el acceso a cargos electivos". 
Devido à reforma constitucional de 1994, que estabeleceu a eleição direta entre os senadores ${ }^{22}$, em 2001 renovou-se, de modo excepcional ${ }^{23}$, a totalidade da Câmara Alta. Isso possibilitou a ampliação do impacto das cotas nessas eleições ao Senado, de forma que a porcentagem de representantes mulheres nesse órgão aumentou de $3 \%$, em 1999, a 35\%, em 200124, e atualmente mantém-se em $38,8 \%{ }^{25}$

É importante ressaltar que a Lei de cotas n. 24.012/91 teve um efeito contágio não somente em outros países como também no âmbito local, já que quase todas as províncias da Argentina adotaram tais leis, que também tiveram um efeito positivo significativo para o aumento do número de legisladoras eleitas ${ }^{26}$.

Dessa forma, as cotas de gênero, na Argentina, tiveram um êxito reconhecido internacionalmente, em virtude de um conjunto de fatores: sistema eleitoral proporcional com listas fechadas e bloqueadas, previsão de mandato de posição, existência de sanções legais para o descumprimento da norma, exigência de aplicação da lei por parte de mulheres políticas e pelo Conselho Nacional da Mulher, promulgação de Decretos para favorecer uma eficaz interpretação e aplicação da lei e decisões do poder jurisdicional que exigem o cumprimento da cota e possibilitam a adequada eficácia da lei.

Existe a preocupação de que a cota mínima de mulheres nas candidaturas converta-se, na prática, num valor máximo. Para analisar se isso ocorre ou não, é necessário examinar se as listas de candidatura superam o requisito mínimo, porque a porcentagem de legisladoras, no parlamento, superior ao mínimo, pode 22 Anteriormente, os senadores eram eleitos indiretamente pelas legislaturas das províncias para um período de nove anos.

23 A Constituição de 1994 prevê que o Senado renova-se, por terços, para um período de seis anos, motivo pelo qual diferentes distritos elegem a totalidade de seus representantes a cada dois anos. Dessa forma, a duração do mandato de um terço dos senadores eleitos em 2001 foi diminuído para dois anos, a do outro terço, a quatro anos e a do terço restante, fixou-se em seis anos.

24 MARÍA CARRIO, Elisa. Los retos de la participación de las mujeres en el Parlamento: Una nueva mirada al caso argentino. In: MÉNDEZ MONTALVO, Myriam; BALLINGTON, Julie (Org.). Mujeres en el Parlamento: Más allá de los números. Estocolmo: IDEA, 2002, p. 135-146.

25 IDEA (INTERNATIONAL INSTITUTE FOR DEMOCRACY AND ELECTORAL ASSISTANCE). Disponível em: <http://www.idea.int/uid/countryview.cfm?id=12>. Acesso em: 4 de fev. de 2014.

26 JONES, Mark. Gender Quotas, Electoral laws, and the Election of Women: Lessons from the Argentine Provinces. Comparative political studies, vol. 31, n. 1, 1998, p.3-21. 
ocorrer como consequência de casos excepcionais e de outros fatores, como a substituição de titulares masculinos por mulheres ${ }^{27}$.

É oportuno salientar que cada província da Argentina elege três senadores, de forma que o partido que concentra o maior número de votos obtém duas vagas e o partido subsequente em quantidade de votos recebe uma vaga. Assim, o mandato de posição que estabelece a obrigação de incluir ao menos uma mulher nos dois primeiros lugares da lista, quando o partido renova dois cargos, garante um mínimo de 33\% de mulheres na lista do Senado para os cargos a renovar. De fato, pode-se observar que existe uma tendência geral a que o partido majoritário envie ao Senado uma candidata, no primeiro lugar, e um candidato, no segundo, enquanto que a força política minoritária é representada por um homem. Pode-se observar que as eleições de 2005 incluíram 37,5\% de legisladoras, mas, apesar disso, quase todas as listas cumpriram o mínimo de 33\%, de forma que esse resultado deveu-se, exclusivamente, ao distrito de Buenos Aires, no qual, excepcionalmente, o partido minoritário apresentou uma mulher no primeiro lugar da lista.

Por outro lado, no caso de listas para a Câmara dos Deputados, apesar de a maioria dos partidos também haver cumprido as cotas, minimamente, em alguns casos as candidatas conseguiram melhores posições além das estritamente estabelecidas por lei. Em 2005, por exemplo, as mulheres foram apresentadas em lugares mais favoráveis em 29\% das listas. Assim, na Câmara dos Deputados, percebe-se mais progresso que no Senado, com relação à superação da cota feminina mínima.

Nesse contexto, é necessário observar essa tendência no tempo para avaliar se as relações entre mulheres e homens nos partidos se aproximarão mais da igualdade e possibilitarão a superação da aplicação mínima da lei. Quando isso ocorra, talvez a lei de cotas já não seja necessária; porém, enquanto não se observa uma mudança efetiva, as cotas constituem uma medida importante na Argentina.

27 MARX, Jutta; CAMINOTTI, Mariana e BORNER, Jutta. Las legisladoras: Cupos de género y política en Argentina y Brasil. 
No Brasil, nenhum partido adotou, de forma voluntária, cotas eleitorais de gênero nas candidaturas partidárias antes de sua previsão legal. As iniciativas anteriores à legislação constituíram cotas para os órgãos diretivos nas esferas partidária e sindical. Em 1991, o partido dos trabalhadores previu uma cota de 30\% para cada sexo nos órgãos diretivos, em 1993 a Central Única dos Trabalhadores (CUT) estabeleceu também um mínimo de $30 \%$ para os dois sexos em suas instâncias de direção e, por fim, em 1997, a Convenção Nacional do Partido Democrático Trabalhista (PDT) previu uma cota mínima de 20\% para as mulheres em suas instâncias diretivas.

No caso do Brasil, a primeira legislação que estabeleceu cotas limitouse ao âmbito das eleições municipais. Trata-se da Lei n. 9.100/95, destinada a regulamentar as eleições de 1996, e que previu uma cota mínima de 20\% para as candidaturas femininas à Câmara Municipal. Não obstante, essa mesma lei também ampliou o número de candidatos que cada partido poderia apresentar, que passou de $100 \%$ a $120 \%$ das vagas em disputa.

Nesse mesmo ano de 1995, a deputada Marta Suplicy havia anunciado o Projeto de Lei para estabelecer uma cota mínima de $30 \%$ para cada sexo nas eleições que observam o sistema de representação proporcional. A mencionada deputada proferiu um discurso no qual comunica os resultados do encontro de legisladoras latino-americanas, realizado em São Paulo, no âmbito do Parlamento LatinoAmericano (PARLATINO), que constituía parte das ações prévias à IV Conferência Internacional da Mulher em Pequim. Marta Suplicy, que na época era deputada federal, ressaltou que, nesse encontro, a discussão sobre as cotas eleitorais de gênero chamou a atenção das parlamentares brasileiras e que, depois de convencerse de sua importância, elaborou um Projeto de Lei sobre tais medidas ${ }^{28}$.

Essa proposta pretendia uma modificação do Código Eleitoral para incluir as cotas de forma permanente. Tal Projeto (n. 783/95) recebeu a assinatura de outras 28 MIGUEL, Sônia Malheiros. A política de cotas por sexo: Um estudo das primeiras experiências no Legislativo brasileiro. Brasília: CFEMEA, 2000. 
26 deputadas de vários partidos e foi apresentado em 10 de agosto de 1995, na Câmara Baixa, época em que se debatia a lei eleitoral destinada a regulamentar as eleições municipais de 1996 (a Lei 9.100/95) ${ }^{29}$.

Entre agosto de 1995 e setembro de 1997, oito projetos legislativos para implementar cotas foram apresentados, três dos quais foram iniciados por legisladores masculinos. A Lei eleitoral n. 9.504/97, que estabeleceu diversas normas para as eleições, foi aprovada em 30 de setembro de 1997 e, no concernente às cotas, previu a reserva de um mínimo de 30\% e um máximo de $70 \%{ }^{30}$ para as candidaturas de cada sexo nas eleições para os membros da Câmara dos Deputados, Câmara Legislativa, Assembleia Legislativa e Câmaras Municipais; ou seja, para as eleições que obedecem ao sistema proporcional, motivo pelo qual se exclui o Senado.

Não obstante, a normativa sobre as cotas não obteve eficácia no país. Em 1994, havia 6,2\% de parlamentares mulheres na Câmara dos Deputados, e em 1998, quando ocorreram as primeiras eleições a esta Casa com vigência da Lei $n$. 9.504/97, a porcentagem de mulheres eleitas foi de 5,6\%, ou seja, sofreu, inclusive, uma leve baixa. Nas eleições posteriores, tampouco houve um crescimento significativo, já que em 2002 foi de 8,2\%; e em 2006, de 8,8\%. Alguns estudos estimavam que, nas eleições de outubro de 2010, a porcentagem de mulheres eleitas para a Câmara dos Deputados iria aumentar entre 30 e $40 \%{ }^{31}$, já que o número de candidatas cresceu de 128 , nas eleições de 2006, a 1.345, no pleito de 2010 , ou seja, de $12,7 \%$ do total de candidatos a $21 \%$. O número de mulheres eleitas, entretanto, não aumentou; ao contrário, diminuiu de 45 (8,7\%) a 44 (8,5\%). No Senado, para cujas eleições não se aplicam cotas, a porcentagem de mulheres eleitas foi um pouco mais alta, de 14,8\% em 2010.

Com essa porcentagem demasiadamente baixa de deputadas (8,8\%), o Brasil, país que elegeu sua primeira presidenta no ano de 2010, encontra-se entre os

29 MIGUEL, Sônia Malheiros. A política de cotas por sexo: Um estudo das primeiras experiências no Legislativo brasileiro.

30 O art. 80 da Lei n. 9.504 previu uma disposição transitória que estabeleceu uma porcentagem mais flexível de um mínimo de 25\% e um máximo de 75\% para as eleições de 1998.

31 Jornal Pequeno, São Luis, 17 de julho de 2010. Disponível em: <http://www.jornalpequeno.com.br/2010/7/17/numero-de-deputadas-federais-deve-crescer-30-projeta-demografo-124817.htm>. Acesso em: 3 de fev. de 2014. 
50 países pior classificados em presença feminina na Câmara Baixa, de acordo com o ranking da União Interparlamentar ${ }^{32}$. Dessa forma, é importante discutir alguns fatores que influem para que a lei de cotas não tenha conseguido lograr o aumento da representatividade feminina no Brasil.

Em primeiro lugar, pode-se destacar a própria redação da lei. O parágrafo $3^{\circ}$ do art. 10 da Lei n. 9.504/97 estabeleceu que cada partido deverá reservar um mínimo de $30 \%$ e um máximo de $70 \%$ para candidaturas de cada sexo. Conforme uma interpretação literal da norma, o partido teria que reservar essa porcentagem de candidatura para as mulheres (ou homens), mas não obrigatoriamente apresentar essa proporção de candidaturas femininas. Assim, o partido poderia deixar vago ou incompleto $30 \%$ das vagas que estariam reservadas para o sexo feminino ou masculino, sem que isso lhe ocasionasse qualquer prejuízo ou sanção ${ }^{33}$. Essa redação normativa foi modificada em 2009, por meio da Lei n. 12.034, que estabelece que cada partido ou coligação preencherá um mínimo de 30\% para candidaturas de cada sexo.

Não obstante, o problema somente foi solucionado de forma parcial. A legislação brasileira permanece sem contemplar, de forma clara, uma sanção por seu descumprimento, como faz a Argentina, por exemplo, ao determinar a não oficialização das listas que não observam as cotas.

Em princípio, seria lógico esperar que o não cumprimento da cota resultasse numa perda de candidatos dos partidos. Não obstante, isso não ocorre, pois a Lei 12.034/09 não pôs fim à cláusula de escape presente na Lei 9.504/97, que autoriza os partidos a aumentar o número de candidatos. Com essa legislação, o total de candidatos que pode ser apresentado por cada partido cresceu de $100 \%$ a $150 \%$. De acordo com Marta Suplicy, a reivindicação das mulheres foi manipulada para aumentar o número de candidaturas, o que diluiu a possibilidade de que a cota contribuísse para gerar um maior investimento nas campanhas das mulheres candidatas $^{34}$.

32 IPU (INTERPARLAMENTARY UNION). Disponível em: <http://www.ipu.org/wmn-e/classif. htm >. Acesso em: 5 de fev. de 2014.

33 ARAÚJO, Clara. Potencialidades e limites da política de cotas no Brasil. Revista Estudos Feministas, vol. 9, n. 1, 2001, p. 231-252.

34 RANGEL, Patrícia. Participação feminina na política institucional: análise do sistema eleitoral 
A possibilidade de oferta de candidatos, incrementada em $50 \%$, representou mais que a porcentagem mínima de $30 \%$ estabelecida para cada sexo. Dessa forma, tal medida anulou uma das pretensões das cotas, que consiste em obrigar a certa diminuição das candidaturas masculinas para ampliar o número de candidatas $^{35}$, com o fim de diminuir a desigualdade de gênero no acesso aos cargos públicos.

Na prática, se em certo distrito elegem-se dez deputados, cada partido está autorizado a postular quinze candidaturas, de maneira que, ao menos quatro destas devem ser contempladas por mulheres (ou homens). Assim, o partido estaria habilitado a apresentar uma candidatura composta por onze homens e quatro mulheres $(150 \%)^{36}$, em vez de sete homens e três mulheres (100\%). Portanto o partido possui garantida a possibilidade de propor um número de homens suficiente para atender à demanda de deputados a eleger ${ }^{37}$, sem que seja necessário investir em candidaturas femininas. Isso representa um incentivo ao descumprimento da lei e, em caso de cumprimento, a que esta não tenha um impacto positivo relevante nas oportunidades eleitorais das mulheres candidatas.

Desde a vigência da lei que estabeleceu cotas no Brasil, em nenhuma das eleições para a Câmara dos Deputados cumpriu-se o mínimo de 30\% de candidatura para as mulheres. Em 1994 (antes da Lei 9.504/97), a porcentagem de candidatas foi de 6,2\%; em 1998 (primeira eleição depois da Lei 9.504/97), de 10,4\%; em 2002, de 11,5\%; em 2006, de 12,7\%; e em 2010, de 21\% ${ }^{38}$. Assim, observa-se, claramente, que a lei que estabelece cotas não foi cumprida em nenhuma das últimas eleições brasileiras para a Câmara dos Deputados.

brasileiro e sugestões de mudança. Relatório Anual do Observatório Brasil da Igualdade de Gênero 2009/2010, Brasília: Secretaria Especial de Política para as Mulheres, 2010, p. 50-57.

35 ARAÚJO, Clara. Por qué las cuotas no funcionan en Brasil?, In: RÍOS TOBAR, Marcela (Org.). Mujer y Política: El impacto de las cuotas de género en América Latina. Santiago: CataIonia, 2008a, p. 129-156.

36 É válido lembrar que, de acordo com a legislação anterior, que afirmava que os partidos deveriam reservar a porcentagem de $30 \%$ para cada sexo, eles poderiam apresentar uma lista com onze homens e nenhuma mulher.

37 Como afirma Araújo (2008a), no Brasil existe, atualmente, um universo potencial de competidores tão amplo que muitas listas não conseguem preencher as vagas "para os homens". Em certos casos, os partidos utilizam candidatos laranjas, ou seja, pessoas, homens ou mulheres, que entram apenas formalmente na composição da lista.

38 TSE (TRIBUNAL SUPERIOR ELEITORAL). Disponível em: < http://www.tse.jus.br/ >. Acesso em: 14 de jan. de 2014. 
Um dos fatores que contribui para a não aplicação das cotas no Brasil, além dos aspectos relacionados com a própria fragilidade normativa da lei, consiste no fato de que a luta por uma legislação de cotas não foi protagonizada por um número significativo de mulheres de distintos partidos e de diversos movimentos de mulheres que se mobilizaram em torno desse tema, como foi o caso da Argentina ${ }^{39}$. A organização feminina, em grande parte dos partidos brasileiros, é muito débil ${ }^{40}$, por isso não houve uma mobilização das mulheres em torno da exigência de aplicação da norma. Uma prova disso é que, nos Tribunais eleitorais do país, predominaram ações propostas por homens que se sentiam prejudicados pela reserva de gênero ${ }^{41}$.

Um dos fatores que é considerado desfavorável para a eleição das mulheres no Brasil é que, neste país, adota-se o sistema proporcional, porém com listas abertas. Cada partido ou coalizão propõe uma lista não ordenada de candidatos ao eleitor, que pode optar por emitir seu voto a favor de uma sigla partidária ou de um candidato. Na prática, a grande maioria dos eleitores prefere a segunda opção. A soma dos votos obtida pelo partido e por seus candidatos, individualmente, dividida pelo coeficiente eleitoral ${ }^{42}$, decidirá o número de vagas obtidas, que se destina aos candidatos individualmente mais votados. O sistema confere um caráter individualizado à competição eleitoral, de forma que os candidatos de um mesmo partido competem entre si. Esse fato, somado ao alto custo das campanhas políticas e à ausência de financiamento público destas, dificulta as candidaturas femininas, que precisam contar com recursos próprios, tanto financeiros como de acesso aos meios de comunicação, contatos pessoais, etc. Assim, a dificuldade das mulheres, muitas vezes, não consiste somente em conseguir ser nomeadas candidatas, mas, principalmente, em conseguir condições efetivas para competir tanto com os candidatos homens de seu partido, que em 39 MARX, Jutta; CAMINOTTI, Mariana; BORNER, Jutta. Las legisladoras: Cupos de género y política en Argentina y Brasil.

40 ARAÚJO Clara; ALVES, José Eustáquio Diniz. Impacto de indicadores sociais e do sistema eleitoral sobre as possibilidades das mulheres nas eleições e suas interações com as cotas. DADOS - Revista de Ciências Sociais, Rio de Janeiro, vol. 50, n. 3, 2007, p. 535-577.

41 AA.VV. Cotas eleitorais para mulheres: uma revisão da jurisprudência dos Tribunais Eleitorais Brasileiros. Revista do Observatório Brasil da Igualdade de Gênero. Brasília: Secretaria Especial de Políticas para as Mulheres, 2009, pp. 76-81.

42 O coeficiente eleitoral é obtido por meio da divisão do número de votos válidos pelo número de vagas disputadas. 
geral possuem mais redes partidárias de apoio, como na disputa exterior ao partido ${ }^{43}$. Isso pode contribuir para que muitas mulheres desistam de apresentarse como candidatas.

Cabe supor que, ainda que as cotas fossem devidamente aplicadas no país, dificilmente poderiam mudar, por si só, esse cenário. É certo que se devem melhorar os aspectos frágeis da lei, como a falta de sanções e o aumento das candidaturas apresentadas pelos partidos. Não obstante, pelas particularidades do sistema eleitoral brasileiro, as cotas somente podem ter uma eficácia limitada ${ }^{44}$. Por isso, muitas mulheres demandam a reforma do sistema político no país. Por outro lado, no caso de a hipótese de reforma não resultar viável, deve-se, além de melhorar a Lei que estabelece cotas para possibilitar sua aplicação e efetividade, adotar outras medidas de incentivo à candidatura das mulheres dentro dos partidos e de meios que favoreçam o desenvolvimento de uma estrutura de campanha para as mulheres ${ }^{45}$.

A Lei 12.034/09 (art. 44, inc. V) estabelece que os partidos devem destinar um mínimo de $5 \%$ do Fundo Partidário à criação e à manutenção de programas de promoção e difusão da participação política feminina. O partido que não observe essa norma terá que acrescentar, no ano subseqüente, 2,5\% do mesmo Fundo para essa finalidade. Por outro lado, a mencionada norma (art. 45, inc. IV) dispõe também que os partidos deverão destinar um mínimo de $10 \%$ da propaganda partidária para promover e difundir a participação política feminina. Trata-se de um avanço, embora ainda muito tímido, no sentido de incentivar as candidaturas femininas.

Outra peculiaridade que vale a pena ressaltar é que, no Brasil, a porcentagem de mulheres eleitas é maior nos distritos de baixa magnitude ${ }^{46}$, o que contrasta 43 NORRIS, Pippa, INGLEHART, R. Rising tide: Gender Equality and Cultural Change around the World. Cambridge: Cambridge University Press, 2003.

44 Como afirma Araújo (2008b), no Brasil, a porcentagem de eleitas não cresce, de forma linear, com o crescimento da porcentagem de candidatas.

45 Como ressaltam alguns autores, se num primeiro momento o obstáculo para as mulheres é conseguir sair candidatas, num segundo momento consiste em construir uma estrutura de campanha. (ARAÚJO, Clara. Partidos políticos e gênero: Mediações nas rotas de ingresso das mulheres na representação política. Revista de Sociologia Política, Curitiba, n. 24, 2005, p. 193-215).

46 Por outro lado, é relevante observar que, no Brasil, os distritos de alta magnitude elegem mais de $60 \%$ dos membros da Câmara dos Deputados; os distritos de média magnitude, em torno de $17 \%$; e os pequenos, também (17\%) (ARAÚjO, Clara. Por qué las cuotas no funcionan en Brasil?, In: RÍOS TOBAR, Marcela (Org.). Mujer y Política: El impacto de las cuotas de género en América Latina.). 
com a suposição de que os distritos de alta magnitude implicam uma maior proporcionalidade e, consequentemente, maiores possibilidades de eleição de candidatas. Uma das explicações para isso indica a existência mais acentuada de certas dificuldades em distritos maiores, como a presença de um mercado eleitoral mais fragmentado e competitivo ${ }^{47}$.

Por fim, é oportuno salientar que a norma que estabelece cotas, no Brasil, apresentou uma ineficácia notória por fatores exatamente opostos aos indicados em relação à Argentina, ou seja: sistema eleitoral de listas abertas (que confere um caráter individualizado da competição) combinado com o alto custo da campanha eleitoral e ausência de financiamento público; inexistência de sanções legais para o descumprimento da norma e o aumento do número de possibilidade de oferta de candidatos pelos partidos; a não exigência de aplicação da lei por parte de mulheres políticas e nem de nenhum órgão do Governo ou da sociedade civil, o que implica a existência de poucas decisões judiciais que exigem o cumprimento da cota e possibilitam a adequada eficácia da lei.

\section{CONSIDERAÇÕES FINAIS}

A Argentina foi o país pioneiro no mundo em legalizar o mecanismo das cotas, ao aprovar a "Ley de Cupos", em 1991. A experiência exitosa da Argentina motivou outros países a debater sobre a implementação de cotas eleitorais de gênero. $O$ processo de redemocratização na América Latina também é considerado um fator que contribuiu para a implementação das cotas legais na região, já que a adoção de tais medidas é conveniente para conferir uma imagem positiva e moderna ao país e aumentar a legitimidade do sistema político, num contexto de reconstrução da democracia ${ }^{48}$. A isso, soma-se o importante incentivo proveniente da IV Conferência sobre a mulher de Pequim (1995), cuja Plataforma de Ação busca garantir o acesso igualitário e a plena participação das mulheres

47 SCHMIDT, Gregory; ARAÚJO, Clara. The Devil's in the Details: Open list voting and gender quotas in Brazil and Peru. Paper presentado para el XXV Congreso Internacional de la Asociación de Estudios Latinoamericano, Las Vegas, Octubre 2004, p. 7-9.

48 ARAÚJO Clara; ALVES, José Eustáquio Diniz. Impacto de indicadores sociais e do sistema eleitoral sobre as possibilidades das mulheres nas eleições e suas interações com as cotas.

DADOS - Revista de Ciências Sociais. 
nas estruturas de poder e tomada de decisões. Dessa forma, a maioria dos países latino-americanos adotoum tais leis na década de noventa e, mais precisamente, em 1996 e 1997, anos imediatamente posteriores à mencionada Conferência.

Os efeitos da aplicação das cotas muda significativamente entre os países. Embora seja importante ressaltar que a alta ou baixa porcentagem de mulheres no Parlamento não se deve, exclusivamente, ao grau de eficácia das cotas, pode-se observar que, passado certo tempo da existência de uma cota, se o país consegue aumentar o número de mulheres no Parlamento, há grandes possibilidades de que as cotas tenham contribuído para isso. Por outro lado, quando a porcentagem de mulheres continua baixa, a indicação é de que as cotas não possuem boa efetividade.

A Argentina constitui exemplo de um país onde as cotas contribuíram, notoriamente, para o incremento da participação das mulheres no Parlamento, ao passo que, no Brasil, não tiveram um efeito positivo. Dessa forma, observou-se que as cotas de gênero, na Argentina, tiveram um êxito reconhecido internacionalmente em virtude de um conjunto de fatores: sistema eleitoral proporcional com listas fechadas e bloqueadas, previsão de mandato de posição, existência de sanções legais para o descumprimento da norma, exigência de aplicação da lei por parte de mulheres políticas e pelo Conselho Nacional da Mulher, promulgação de Decretos para favorecer uma eficaz interpretação e aplicação da lei e decisões do poder jurisdicional que exigem o cumprimento da cota e possibilitam a adequada eficácia da lei.

Por fim, é oportuno salientar que a norma que estabelece cotas no Brasil apresentou uma ineficácia notória por fatores exatamente opostos aos indicados em relação à Argentina, ou seja: sistema eleitoral de listas abertas (que confere um caráter individualizado da competição) combinado com o alto custo da campanha eleitoral e ausência de financiamento público, a inexistência de sanções legais para o descumprimento da norma e o aumento do número de possibilidade de oferta de candidatos pelos partidos, a não exigência de aplicação da lei por parte de mulheres políticas nem de nenhum órgão do Governo ou da sociedade civil, o que implica a existência de poucas decisões judiciais que exigem o cumprimento da cota e possibilitam a adequada eficácia da lei. 
Cabe supor que, ainda que as cotas fossem devidamente aplicadas no país, dificilmente poderiam mudar, por si só, esse cenário. É certo que se devem melhorar os aspectos frágeis da lei, como a falta de sanções e o aumento das candidaturas apresentadas pelos partidos. Não obstante, pelas particularidades do sistema eleitoral brasileiro, as cotas somente podem ter uma eficácia limitada. Por isso, muitas mulheres demandam a reforma do sistema político no país. Por outro lado, no caso de a hipótese de reforma não resultar viável, deve-se, além de melhorar a lei que estabelece cotas para possibilitar sua aplicação e efetividade, adotar outras medidas de incentivo à candidatura das mulheres dentro dos partidos e de meios que favoreçam o desenvolvimento de uma estrutura de campanha para as mulheres.

\section{REFERÊNCIAS}

AAVV. Cotas eleitorais para mulheres: uma revisão da jurisprudência dos Tribunais Eleitorais Brasileiros. Revista do Observatório Brasil da Igualdade de Gênero. Brasília: Secretaria Especial de Políticas para as Mulheres, 2009, pp. 76-81.

AQUINO DE SOUZA, Cristiane. Cotas eleitorais para a igualdade de gênero: uma perspectiva jurídico-constitucional. Anuario de Derecho Constitucional Latinoamericano, ano XVI, 2010, p. 239-253.

ALLEGRONE, Norma. Ley de Cupo Femenino: Su aplicación e interpretación en la República Argentina. Buenos Aires: Fundación para el Desarrollo en Igualdad - FUNDAI, Fundación Friedrich, 2002.

ALLES, Santiago. “¿Hacia la consolidación política? Cambios en la «estructura de oportunidades electorales» de las mujeres en Argentina. América Latina Hoy, n. 47, 2007, p. 123-154.

ARAÚJO, Clara. Por qué las cuotas no funcionan en Brasil? In: RÍOS TOBAR, Marcela (Org.). Mujer y Política: El impacto de las cuotas de género en América Latina. Santiago: Catalonia, 2008a, p. 129-156.

ARAÚJO, Clara. Mujeres y elecciones legislativas en Brasil: Las cuotas y su (in) eficacia. In: ARCHENTI, Nélida; TULA, María Inés (Org.). Mujeres y política en América Latina: Sistemas electorales y cuotas de género. Buenos Aires: Heliasta, 2008b, p. 87-106. 
ARAÚJO, Clara; GARCÍA, Ana Isabel. The experience and the impact of quotas in Latin America. In: DAHLERUP, Drude (Org.). Women, Quotas and Politics. New York: Routledge, 2007.

ARAÚJO, Clara; ALVES, José Eustáquio Diniz. Impacto de indicadores sociais e do sistema eleitoral sobre as possibilidades das mulheres nas eleições e suas interações com as cotas. DADOS - Revista de Ciências Sociais, Rio de Janeiro, vol. 50, n. 3, 2007, p. 535-577.

ARAÚJO, Clara. Partidos políticos e gênero: Mediações nas rotas de ingresso das mulheres na representação política. Revista de Sociologia Política, Curitiba, n. 24, 2005, p. 193-215.

ARAÚJO, Clara. Potencialidades e limites da política de cotas no Brasil. Revista Estudos Feministas, vol. 9, n. 1, 2001, p. 231-252.

DURRIEU, Marcela. Se dice de nosotras. Buenos Aires: Catálogos Editora, 1999.

IDEA (INTERNATIONAL INSTITUTE FOR DEMOCRACY AND ELECTORAL ASSISTANCE). Disponível em: <http://www.idea.int/uid/countryview.cfm?id=12>. Acesso em 4: de fev. de 2014.

IPU (INTERPARLAMENTARY UNION). Disponível em: <http://www.ipu.org/wmn-e/classif. htm>. Acesso em 5 de fev. de 2014.

JONES, Mark. Gender Quotas, Electoral laws, and the Election of Women: Lessons from the Argentine Provinces. Comparative political studies, vol. 31, n. 1, 1998, p.3-21.

JORNAL PEQUENO. Número de deputadas federais deve crescer 30\%, projeta demógrafo. Jornal Pequeno, São Luis, 17 de julho de 2010. Disponível em: <http://www.jornalpequeno. com.br/2010/7/17/numero-de-deputadas-federais-deve-crescer-30-projeta-demografo124817.htm>. Acesso em: 3 de fev. de 2014.

LÁZZARO, Alejandra. El papel de la justicia en la resolución de conflictos de género: El caso de Argentina. In: ARCHENTI, Nélida; TULA, María Inés (Org.). Mujeres y política en América Latina: Sistemas electorales y cuotas de género. Buenos Aires: Heliasta, 2008, p. 55-64.

MARÍA CARRIO, Elisa. Los retos de la participación de las mujeres en el Parlamento: Una nueva mirada al caso argentino. In: MÉNDEZ MONTALVO, Myriam e BALLINGTON, Julie (Org.). Mujeres en el Parlamento: Más allá de los números. Estocolmo: IDEA, 2002, p. 135-146.

MARX, Jutta; CAMINOTTI, Mariana; BORNER, Jutta. ¿En pie de igualdad? Quince años de cupo femenino en Argentina. In: RÍOS TOBAR, Marcela (Org.). Mujer y política: El impacto de las cuotas de género en América Latina. RÍOS Santiago/Chile: Catalonia, 2008. 
MARX, Jutta. Las legisladoras: Cupos de género y política en Argentina y Brasil. Buenos Aires: Siglo XXI, 2007.

NORRIS, Pippa; INGLEHART, R. Rising tide: Gender Equality and Cultural Change around the World. Cambridge: Cambridge University Press, 2003.

MIGUEL, Sônia Malheiros. A política de cotas por sexo: Um estudo das primeiras experiências no Legislativo brasileiro. Brasília: CFEMEA, 2000.

RANGEL, Patrícia. Participação feminina na política institucional: análise do sistema eleitoral brasileiro e sugestões de mudança. Relatório Anual do Observatório Brasil da Igualdade de Gênero 2009/2010, Brasília: Secretaria Especial de Política para as Mulheres, 2010, p. 50-57.

SCHMIDT, Gregory e ARAÚJO, Clara. The Devil's in the Details: Open list voting and gender quotas in Brazil and Peru. Paper presentado para el XXV Congreso Internacional de la Asociación de Estudios Latinoamericano, Las Vegas, Octubre 2004, p. 7-9.

TSE (TRIBUNAL SUPERIOR ELEITORAL). Disponível em: < http://www.tse.jus.br/ >. Acesso em: 14 de jan. de 2014.

Recebido em: set/2014 Aprovado em: out/2014 